Proceedings of SALT 21: 652-673, 2011

\title{
Toward a more fine-grained theory of temporal adverbials*
}

\author{
Daniel Altshuler \\ Heinrich-Heine-Universität Düsseldorf
}

\begin{abstract}
In this paper I propose that a core property of adverbial meaning is the ability (or the lack thereof) of an adverbial to introduce a new time discourse referent. The core data comes from that same day in narrative discourse. I argue that unlike other previously studied temporal adverbials - which introduce a new time discourse referent and relate it to the speech time or a previously mentioned time-that same retrieves two salient times from the input context, i.e. it is 'twice-anaphoric', without introducing one of its own. Moreover, I argue that the adverb currently is like that same day in not introducing a new time discourse referent; it constrains the temporal location of a described eventuality relative to a salient time previously introduced into the discourse context. The analysis that I propose is implemented within Compositional Discourse Representation Theory. It illustrates how adverbial meaning can be integrated within a more general theory of temporal interpretation.
\end{abstract}

Keywords: adverbials, anaphora, deixis, compositional discourse representation theory

\section{The puzzle}

Adverbs can be described as being deictic, anaphoric, both or neither. Comparing the discourse in (1) to those in (2)-(5) helps to illustrate these distinctions. In (1), the adverbless clauses - taken from the middle of a story-exemplify narrative progression: the temporal location of each described event depends on the temporal location of the previous event and the times of the described events correlate with the order of appearance.

(1) a. ...Sue gave Fido a bath and cleaned our house.

b. My wife hired her and gave her a check for one month in advance...

\footnotetext{
* The idea for this paper developed while talking about narrative progression with Rajesh Bhatt over Moroccan tea at Mosaic (Northampton, MA). In addition to Rajesh, thanks to Yael Sharvit and the participants in her Semantics Seminar (UConn, Fall 2010) for inviting me to present some of the material found here. Thanks also to Roger Schwarzschild, Sam Cumming, Barbara Partee, Matthew Stone and the participants at SALT 21 for their insight. The usual disclaimers apply.
} 
Towards a more fine-grained theory of temporal adverbials

In (2), the times of the described events also correlate with the order of appearance. However, unlike in (1b), the temporal location of the hiring event described in (2b) does not depend on the discourse context. We infer that the hiring took place the day prior to the speech time regardless of (2a). For this reason yesterday is typically called a deictic adverb - its meaning is dependent on the context of utterance.

(2) a. ...Sue gave Fido a bath and cleaned our house.

b. Yesterday, my wife hired her and gave her a check for one month in advance...

In (3), we see narrative progression as in (1). The difference is that the latter is more specific about the temporal location of the hiring: the day after requires this event to be located after a salient day previously mentioned in the discourse (i.e. May 12, 1984). Adverbs whose meaning is dependent on discourse context in this way are typically called anaphoric.

(3) a. On May 12, 1984, Sue gave Fido a bath and cleaned our house.

b. The day after, my wife hired her and gave her a check for one month in advance.

In (4), the times of the described events correlate with the order of appearance as in (1)-(3). However, the temporal location for the hiring event depends neither on the discourse context or the context of utterance. Such is the case because on June 13,1985 is a proper name adverbial, referring to the only June 13, 1985 in the history of the world. Adverbs of this sort are neither deictic or anaphoric (cf. Kamp and Reyle's 1993 notion of calendar adverbial).

(4) a. On May 12, 1984, Sue gave Fido a bath and cleaned our house.

b. On June 13, 1985, my wife hired her and gave her a check for one month in advance.

Finally, in (5), there are two possible interpretations: (i) the hiring event took place on the closest Sunday after the house cleaning or (ii) the hiring event took place on the closest Sunday prior to the speech time (cf. Kamp \& Reyle 1993). The former interpretation demonstrates the anaphoric usage of on Sunday, viz. the day after in (3), while the latter interpretation demonstrates the deictic usage of on Sunday, viz. yesterday in (2).

(5) a. 3 weeks ago on Friday, Sue gave Fido a bath and cleaned our house.

b. On Sunday, my wife hired her and gave her a check for one month in advance. 
The goal of the paper is to address what semantic ingredients are common to all temporal adverbs. That is, if one were given a particular expression $v$, what would be the semantic criteria to argue that $v$ is a temporal adverbial? Saying that $v$ is [+/- anaphoric] and [+/-deictic] is crucial but not distinguishing criteria since nominal expressions can also be classified in this way, viz. Fig. 1 below. ${ }^{1}$

\begin{tabular}{|c|c|c|}
\hline & ANAPHORIC & DEICTIC \\
\hline $\begin{array}{c}\text { May 12, 1984/ } \\
\text { Frédéric François Chopin }\end{array}$ & No & No \\
\hline Yesterday/I & No & Yes \\
\hline the day after/ the composer & Yes & No \\
\hline on Sunday/he & Yes & Yes \\
\hline
\end{tabular}

Figure 1 Typology of anaphoric and deictic expressions (to be revised)

While there has been plenty of work on the semantics of particular temporal adverbs $^{2}$, there has been virtually no (recent) work on the semantic properties of temporal adverbials more generally. ${ }^{3}$ The likely reason for this is that there appears to be a consensus about the semantic function of temporal adverbs: to introduce a new time discourse referent (DREF). This DREF serves as the temporal location, or REFERENCE TIME, for the described event(s). The DREF introduced by deictic adverbs is related to the speech time, while the DREF introduced by anaphoric adverbs is related to discourse context. To the best of my knowledge, most (if not all) researchers working on temporal interpretation assume some version of this idea (even if implicitly).

The beauty of such an analysis_pioneered by Partee 1984 (building on Hinrichs 1981) - is that it allows us to have an elegant theory of temporal anaphora. The crux of Partee's analysis is as follows: (i) described events are

${ }^{1}$ Cf. Vegnaduzzo 2001, where temporal adverbs are classified as being inherently deictic, inherently anaphoric or contextually anaphoric. I choose the classifications that I do because it is convenient to relate the adverbial distinctions to two binary features: +/- anaphoric and +/- deictic. These features are not meaning components, but just descriptive abbreviations.

${ }^{2}$ For example, see Lee \& Choi 2009, Altshuler 2009, Hunter 2011, Ritz et al. 2012 on the semantic properties of now, following Kamp's (1971) classic work. See also Pratt \& Francez 2001, Von Stechow 2002 and Burnett 2011 on (temporal) adverbs of quantification. There is also a vast body of research on prepositional phrases like for 2 hours and in an hour.

${ }^{3}$ The only work that I know of comes from Kamp \& Reyle 1993 (Chapter 5), Vegnaduzzo 2001, Kamp \& Schiehlen 2002 and Altshuler 2009; 2010. 
Towards a more fine-grained theory of temporal adverbials

always contained within the REFERENCE TIME, where (ii) the REFERENCE TIME is either the time denoted by a temporal adverbial or, (iii) in cases where a temporal adverbial is not present, it is the time 'just after' a previously mentioned discourse event. ${ }^{4}$ For example, according to this theory, the cleaning event described in (1a) would be located within the time 'just after' the bath-giving event described by the previous clause. ${ }^{5}$ Similarly, the hiring event described in (1b) would be located within the time 'just after' the cleaning event described in (1a), and so on. In this way, we account for the narrative progression in (1).

In (2b)-(5b), the hiring event would be located within the time denoted by the adverbial and not the time 'just after' the cleaning event described in (2a)(5a). This is guaranteed via a deterministic 'update' of the REFERENCE TIME by the temporal adverbial, which fixes the temporal location of a described event; previously established REFERENCE TIMES no longer play an 'active' role. This is important in discourses like (6), where there hiring is understood to have taken place on May 11, 1984 and not the time 'just after' the cleaning event.

(6) a. On May 12, 1984, Sue gave Fido a bath and cleaned our house.

b. The day before, my wife hired her and gave her a check for one month in advance...

Despite the elegance of this analysis, I argue in this paper that a temporal adverbial need not introduce a new time DREF into the discourse context-in addition to being $+/$ - deictic and $+/$ - anaphoric, a core property of adverbial meaning is whether an adverb is +/- in its ability to introduce a new time DREF. My argument is based on adverbial transparency to narrative progression. To see what I have in mind, consider the discourse in (7), which is like the other discourses we have seen thus far except that it has the adverb that same day in (7b). What is interesting about this discourse is that that same day does not alter the narrative progression that we saw in (1) - the adverb is, as it were, 'transparent to the progress'. That is, specifying that the hiring took place on the same day as the house cleaning does not block the additional inference that the hiring took place after the house cleaning.

(7) a. On May 12, 1984, Sue gave Fido a bath and cleaned our house.

b. That same day, my wife hired her and gave her a check for one month in advance.

\footnotetext{
${ }^{4}$ Here I ignore the fact that grammatical elements other than adverbials (e.g. when-clauses) could also supply a REFERENCE TIME.

5 As noted by Dowty (1986), 'just after' is deliberately vague. "The point is that...reference times "immediately" follow one another in the sense that each successive sentence presents the very next event that transpires that is important enough to merit the speaker's describing it to the hearer, given the purpose of the narration" (ibid: 47); see also discussion in Kamp 1979.
} 
The parallel between (1) and (7) is surprising and is problematic for Partee's (1984) theory and any other theory of temporal anaphora that assumes the semantic function of temporal adverbs is to introduce a novel REFERENCE TIME and that narrative structure results from introduction of novel reference times. According to such an analysis, the hiring event described in (7b) takes place at the reference time that is introduced by the adverbial that same day. If we make the seemingly harmless assumption that this adverbial denotes a salient day previously mentioned in the discourse, then we would say that that same day picks out May 12, 1984. While this correctly predicts that the hiring event described in (7b) took place on this day, nothing is said about how this event is ordered with respect to the cleaning event described in (7a), which also takes place on May 12, 1984. Put differently, because the life span of the reference time introduced by cleaned our house in (7a) is "cut off" by the that same day in (7b), we can't account for the understood narrative progression.

Note that this argument can be replicated with related adverbs like that same week in (8), as well as that day and that very day in (9). Here we infer that the hiring event followed the house-cleaning event whether or not there is an adverb in the b-sentences.

(8) a. The $1^{\text {st }}$ week in April, Sue gave Fido a bath and cleaned our house.

b. (That same week) my wife hired her and gave her a check for one month in advance.

(9) a. On May 12, 1984, Sue gave Fido a bath and cleaned our house.

b. (\{That day/that very day $\})$ my wife hired her and gave her a check for one month in advance.

Moreover, the argument can be replicated in non-narrative discourse. For example, consider (10) which exemplifies a flashback whether that same day is present or not - the hiring described in (10b) is understood to precede the house cleaning described in (10a).

(10) a. On May 12, 1984, Sue gave Fido a bath and cleaned our house.

b. (That same day) My wife had hired her and had given her a check for one month in advance...

With that same day in (10b), the hiring event is understood to take place on May 12,1984 . If we once again make the seemingly harmless assumption that that same day updates the REFERENCE TIME to a salient day previously mentioned in the discourse, then we would account for this inference. However, in so doing, nothing would be said about how the hiring event is ordered with respect to the cleaning event described in (10a), which also takes place on May 12, 1984. Put differently, because the life span of the REFERENCE TIME introduced by cleaned 
Towards a more fine-grained theory of temporal adverbials

our house in (10a) is "cut off” by that same day in (10b), we can't account for the understood narrative regression in (10b).

To round out the empirical picture of when that same day and related adverbs are used, first consider the discourse below, where we infer the so-called PARALLEL discourse relation in $(11 \mathrm{~b}, \mathrm{c})$ with or without that same day-i.e. the events described in $(11 b, c)$ are parallel with regard to the question under discussion (i.e. what happened two days ago in response to some good Puerto Rican food being made) and thus there is no order that these events are understood to have occurred in (though both are understood to follow the event described in (11a)).

(11) a. My mother made a lot of good Puerto Rican food.

b. Two days ago, Jessica ate chicken and plantains.

c. (That same day) Sam ate rice and beans.

Unlike, (7)-(10), however, (11) is not a problem for Partee's theory. Let's suppose that (11) is uttered on a Sunday. Then the REFERENCE TIME introduced by two day ago in (11b) is Friday. If we, once again, make the seemingly harmless assumption that that same day denotes a salient day previously mentioned in the discourse, then the REFERENCE TIME in (11c) is also Friday. Therefore, Friday is the temporal location for both eating events described in (11b) and (11c) and since no more information is provided, it is not surprising that there is no order that these events are understood to have occurred in (relative to one another).

The discourse in (11) nicely illustrates what distinguishes that same day and related adverbs from those considered at the outset of this paper: the time described by that same day and related adverbs always preserves the temporal structure of a discourse, i.e. they are transparent. Compare (11) to (12), where that same day is replaced by the various kinds of adverbs that were discussed at the outset of the paper. No matter whether an adverb is deictic, anaphoric, both or neither, (12c) shows that the time described by the adverbial in question may affect the temporal structure of a discourse, i.e. (12) does not preserve the temporal structure of (11): the event of eating rice and beans must be understood as either following or preceding the event of eating chicken and plantains.

(12) a. My mother made a lot of good Puerto Rican food.

b. Two days ago, Jessica ate chicken and plantains.

c. \{Yesterday/Today/Tomorrow/The day before/The day after/On Feb. $15,1981 /$ On Sunday Sam ate rice and beans.

The fact that anaphoric adverbs like the day before and the day after may affect the temporal structure of a discourse is not surprising - the time that they describe is only compatible with narrative regression and narrative progression 
respectively. With regard to deictic adverbs like yesterday, today and tomorrow, things are more complex. In principle, they are compatible with narrative progression or narrative regression since the time they describe is independent of the surrounding discourse. The same goes for calendar adverbials like on February 15, 1981. By the same token, the fact that these adverbs describe a time that is independent of the surrounding discourse is the reason why they may affect the temporal structure of a discourse, e.g. for any given temporal location $t$ in a given story, the day before now is either before or after $t$.

The fact that most adverbs are non-transparent, i.e. they may affect the temporal structure of a discourse, is what allowed Partee (1984) to incorporate adverbs into a theory of temporal anaphora in such an elegant way-temporal adverbs, like eventive sentences, introduce a new REFERENCE TIME and thereby "cut off" the life span of previously introduced REFERENCE TIME. However, this section demonstrated that some adverbs are transparent, i.e. they never affect the temporal structure of a discourse, and this fact is problematic for Partee's theory and any other theory of temporal anaphora that assumes the semantic function of temporal adverbs is to introduce a novel reference time and that narrative structure results from introduction of novel reference times.

One possible reply to this conclusion is to say that the transparency of that same day and related adverbials in narrative discourse is a reflex of its semantics, combined with independently motivated temporal constraints imposed by the socalled coherence relations, which characterize the possible ways in which successive utterances could be connected to form a coherent discourse (Hobbs $1978 ; 1979 ; 1990)$. For example, one may think that the so-called OCCASION relation defined in (13) below is responsible for the narrative progression in (7), with or without that same day.

(13) $\operatorname{OCCASION}(\varphi, \psi): \mathrm{e}_{\psi}$ is contingent on $\mathrm{e}_{\varphi}{ }^{6}$

"if OCCASION holds between sentences $\varphi$ and $\psi$, then the eventuality $\mathrm{e}_{\psi}$ described by $\psi$ is contingent on the eventuality $\mathrm{e}_{\varphi}$ described by $\varphi . "$

The question that arises is: Why should OcCASION hold in (7)? According Hobbs, $(1976 ; 1979 ; 1990)$, a particular coherence relation is inferred based on various factors. Chief among these is world knowledge (see also Lascarides \& Asher 1993; Kehler 2002). Moreover, the inferred coherence relation "must be consistent with any temporal relations imposed by the tenses used and thus these temporal relations may constrain the set of coherence relations that can be inferred" (Kehler 2002: 191). Since the (simple) past tense is compatible with

${ }^{6}$ The contingency relationship is often defined in terms of an event's "change of state" or its consequent state relative to the other event, e.g. $e_{\psi}$ is contingent on $e_{\varphi}$ iff $e_{\psi}$ contained within the consequent state of $\mathrm{e}_{\varphi}$ (Moens \& Steedman 1988, Webber 1988, Hobbs 1990). As a result of the contingency relationship, $\mathrm{e}_{\psi}$ and $\mathrm{e}_{\varphi}$ are ordered by the complete precedence relation: $\mathrm{e}_{\varphi}<_{\mathrm{t}} \mathrm{e}_{\psi}$ 
Towards a more fine-grained theory of temporal adverbials

most (if not) all coherence relations, the OCCASION should be inferable in (7) based on our assumptions about the world. This, however, seems unlikely. If world knowledge tells us anything about when people work in relation to when they are hired is that people typically begin work after being hired. In any case, it is clearly not world knowledge that is forcing one to conclude in (7) that Sue cleaned another person's dog and house as a volunteer. ${ }^{7}$

Note that the claim here is not that inferences about event ordering are divorced from constraints imposed by coherence relations. Research on discourse coherence has persuasively shown such relations are crucial to our understanding of temporal interpretation. ${ }^{8}$ Rather, the claim here is that coherence relations are not responsible for the narrative progression in (7). ${ }^{9}$ And if that is right, then we need an alternative analysis for discourses of this sort. In particular, we need a theory in which that same day does not block off independent rules of the grammar that account for the narrative progression (or any other temporal ordering that may arise with that same day).

In the next two sections, I will analyze a simplified version of (7) using Compositional Discourse Representation Theory (CDRT, Muskens 1995). The punch line of the analysis is: some temporal adverbials do not introduce a new time DREF into the discourse context, but merely constrain the temporal location of a described event relative to a salient time DREF previously introduced into the discourse context. I propose that the semantic function of that same day is twofold: (i) find a salient time antecedent $t$ that has the property of being a day and (ii) require that $t$ take place throughout an already established REFERENCE TIME, within which the described event takes place. The idea is, then, that that same day retrieves two salient times from the input context, i.e. it is 'twiceanaphoric'. This is what I propose to be the crucial difference between that same day and an adverb like the day after, which introduces a new DREF into the discourse context and is only 'once-anaphoric'. A nice result of the analysis is that it is easy to implement with a more general theory of temporal interpretation, i.e. without any significant changes to well-known approaches to the meaning of tense and aspect.

\footnotetext{
${ }^{7}$ Note that some researchers have posited axioms that entail that the OCCASION relation is inferred by default (see Lascarides and Asher 1993). While this would potentially explain why there is narrative progression in (7), it is unclear why the default is overridden in examples like (i) below.

(i) \#At five o'clock, Harry took off his boots, sat down and walked in.

${ }^{8}$ See e.g. Hobbs 1979; 1990, Mann \& Thompson 1988, Lascarides \& Asher 1993, Knott 1996, Knott \& Mellish 1996, Kehler 2002, Webber et al. 2003, among many others.

9 As noted by Jerry Hobbs (p.c.), another possibility is to say that 'and', which rarely has the meaning of simple conjunction, is responsible for the narrative progression in (7). Such a view, however, would not explain the narrative progression in discourses like (ii).
}

(ii) Sue cleaned our house on May 12, 1984. That same day, Lev hired her. 
I conclude the paper by arguing that the adverb currently is like that same day in constraining the temporal location of a described event relative to a salient time DREF previously introduced into the discourse context. Currently differs from that same day, however, in its ability to have a deictic interpretation (in addition to an anaphoric one), viz. on Sunday. Moreover, unlike other temporal adverbials, currently is typologically bizarre in having an affinity for stative VPs. I briefly discuss what this observation may mean for the interface between aspectual and adverbial meaning.

\section{The framework}

This section briefly outlines Muskens' (1995) CDRT that underlies the analysis proposed in this paper. This framework is chosen over, e.g. classic DRT proposed by Hans Kamp and colleagues (Kamp 1981, Kamp \& Reyle 1993), in order to provide dynamic meanings of temporal expressions as terms in a typed $\lambda$ calculus. Moreover, while other compositional presentations of DRT exist, ${ }^{10} \mathrm{I}$ find Muskens' presentation especially straightforward.

CDRT treats the syntax of DRT-i.e. the language of Discourse Representation Structures (DRSs) - as an abbreviation for more elaborate terms. Muskens starts from the assumption that DRSs constitute a binary relation between input and output assignments (embeddings in DRT terms). This relation is responsible for the dynamic nature of DRT. Assignments are functions from the set of DREFs to the domain. A DRS K is a pair of a set of DREFs $\delta, \ldots, \delta$ ' (i.e. the universe of $\mathrm{K}$ ) and a set of conditions $\mathrm{C}, \ldots, \mathrm{C}^{\prime}$. As illustrated below, in (14), the meaning of a DRS K is the set of pairs of assignments $\langle f, g\rangle$ such that $g$ differs from $f$ at most with respect to the values that they assign to the DREFs in the universe of $\mathrm{K}$, written $f\left[\delta, \ldots, \delta^{\prime}\right] g$, and $g$ makes the conditions of $\mathrm{K}$ true (cf. Groenendijk and Stokhof 1991).

$$
\begin{array}{ll}
\text { a. } & \left.\mathbb{[} \delta, \ldots, \delta^{\prime} \mid \mathrm{C}, \ldots, \mathrm{C}^{\prime}\right] \rrbracket^{2 n}= \\
\text { b. } & \left\{\langle f, g\rangle \mid f\left[\delta, \ldots, \delta^{\prime}\right] g \& g \in \llbracket C \mathbb{W}^{2 n} \cap \ldots \cap \llbracket \mathrm{C}^{\prime} \rrbracket^{2 m}\right\}
\end{array}
$$

CDRT mimics the dynamic nature of DRT in type logic by adopting assignments in the object language. In particular, the set of primitive types-i.e. one that includes individuals (type e), intervals of time (type i), eventualities (type $\boldsymbol{\varepsilon}$ ), possible worlds (type $\boldsymbol{\omega}$ ) and truth-values (type $\mathbf{t}$ ) - is enriched with type $\mathbf{s}$ for

\footnotetext{
${ }^{10}$ Cf. $\lambda$-DRT of Latecki and Pinkal (1990), Groenendijk and Stokhof's $(1990,1991)$ DPL, Asher's (1993) bottom-up DRT and the compositional version of DRT proposed by van Eijck and Kamp (1996). These other proposals could be adapted along similar lines to what is presented here.
} 
Towards a more fine-grained theory of temporal adverbials

environments, which behave like assignments; ${ }^{11}$ they "...are very much like the program states that theoretical computer scientists talk about, which are lists of the current values of all variables in a given program at some stage of its execution" (Muskens 1996: 11). In this paper, I assume the set of primitive types below, which differs from Muskens 1995 only in that I disregard possible worlds in the ontology. This is done for the sake of simplicity.

\section{DEFINITION 1 (Types)}

- e, i, $\varepsilon, \mathrm{t}, \mathrm{s} \in \mathrm{Typ}$

- $(\mu \alpha) \in$ Typ, if $\mu, \alpha \in$ Typ

To see how environments are made part of the object language, consider (15). The DRS in (15a) serves as an abbreviation for the type $s(s t)$ expression in (15b), where $i$ and $j$ are variables over environments. Unlike in DRT, drefs in CDRT are functions that take an environment as an argument and return an object in that environment. Assuming that this object can be of any type, drefs are type s $\alpha$, where $\alpha \in$ Typ. Moreover, conditions are treated as predicates of environments, i.e. expressions of type st.

$$
\begin{array}{ll}
\text { a. } & {\left[\delta_{\mathrm{s} \alpha}, \ldots, \delta_{\mathrm{s} \alpha}^{\prime} \mid \mathrm{C}_{\mathrm{st}}, \ldots, \mathrm{C}_{\mathrm{st}}^{\prime}\right]} \\
\text { b. } & \lambda i \lambda j . i\left[\delta, \ldots, \delta^{\prime}\right] j \wedge \mathrm{Cj} \wedge \ldots \wedge \mathrm{C}^{\prime} j
\end{array}
$$

Unlike (14a), (15a) no longer gets a direct interpretation. Rather, the form that it abbreviates, namely (15b), gets assigned an interpretation. The meaning of a sentence $\varphi$ is a relation that holds between environments $i$ and $j$ just in case $j$ is an environment that might result from the interpretation of $\varphi$ in environment $i$.

Below, I provide examples of expressions of various types that are found in the analysis that follows.

\section{DEFINITION 2 (Constants and variables)}

For any type $\alpha \in \mathrm{Typ}$, there is a denumerable set of $\alpha$-constants $\operatorname{Con}_{\alpha}$ and a denumerably infinite set of $\alpha$-variables $\operatorname{Var}_{\alpha}$, including the following sets:

- $\mathrm{Con}_{\mathrm{e}}=\{$ sue,$\ldots\}$

- $\mathrm{Con}_{\mathrm{i}}=\{$ may.12.1984,... $\}$

- Con $_{\text {et }}=\{$ house,$\ldots$, jacket,$\ldots\}$

- $\mathrm{Con}_{\mathrm{it}}=\{$ day, $\ldots$, week,...$\}$

- $\operatorname{Con}_{(\mathrm{e}(\mathrm{tt}))}=\{$ enter,...,clean.our.house,,..$\}$

- $\operatorname{Var}_{(\mathrm{si}(\mathrm{s}(\mathrm{st})))}=\left\{Q, Q^{\prime}, \ldots\right\}$

- $\operatorname{Con}_{(\mathrm{e}(\mathrm{e}(\mathrm{t} t)))}=\{$ hire, $, \ldots, \mathrm{read}, \ldots\}$

- $\mathrm{Con}_{\mathrm{se}}=\left\{\mathrm{u}_{1}, \mathrm{u}_{2}, \ldots, \mathrm{u}_{1}^{\prime}, \mathrm{u}_{2}^{\prime}, \ldots, \mathrm{u}\right\}$

- $\operatorname{Var}_{(\mathrm{s} \varepsilon(\mathrm{s}(\mathrm{st})))}=\left\{P, P^{\prime}, \ldots\right\}$

- $\operatorname{Var}_{\mathrm{s}}=\left\{i, i^{\prime}, \ldots, j, j^{\prime}, \ldots, k, k^{\prime}\right\}$

- $\operatorname{Var}_{\mathrm{se}}=\left\{x, x^{\prime}, \ldots\right\}$

\footnotetext{
${ }^{11}$ The term environment comes from Stone 1997; Muskens uses the loaded notion state instead.
} 
- $\mathrm{Con}_{\mathrm{si}}=\left\{\mathrm{t}_{1}, \mathrm{t}_{2}, \ldots, \mathrm{t}_{1}^{\prime}, \mathrm{t}_{2}^{\prime}, \ldots, \mathrm{t}\right\}$

- $\mathrm{Con}_{\mathrm{s} \varepsilon}=\left\{\mathrm{e}_{1}, \mathrm{e}_{2}, \ldots, \mathrm{e}_{1}^{\prime}, \mathrm{e}_{2}^{\prime}, \ldots, \mathrm{e}\right\}$
- $\operatorname{Var}_{\mathrm{si}}=\left\{t, t^{\prime}, \ldots\right\}$

- $\operatorname{Var}_{\mathrm{s} \varepsilon}=\left\{e, e^{\prime}, \ldots\right\}$

Let us now consider abbreviations that are relevant to the analysis proposed in this paper. Def. 3 expresses that $i$ differs from $j$ at most with respect to the values that they assign to $\delta$. Note that ST is a predicate that is true of drefs, i.e. it stands for the predicate "is a DREF of type (s $\alpha)$." This predicate is used by Muskens to ensure that DREFs and environments behave as variables and assignments respectively (see AX1-AX3 in Muskens 1995: 6-7).

\section{DEFINITION 3}

If $\delta$ is a term of type s $\alpha$, where $\alpha \in$ Typ, then $i[\delta] j$ abbreviates the conjunction of:

(i) $\forall \delta_{\text {s } \alpha}^{\prime}\left[\left[\mathrm{ST}(\mathrm{s} \alpha) \mathrm{t}\left(\delta^{\prime}\right) \wedge \delta^{\prime} \neq \delta\right] \rightarrow \delta^{\prime}(j)=\delta^{\prime}(i)\right]$ and

(ii) the conjunction of $\forall \delta^{\prime}{ }_{\mathrm{s} \beta}\left[\mathrm{ST}(\mathrm{s} \beta) \mathrm{t}\left(\delta^{\prime}\right) \rightarrow \delta^{\prime}(j)=\delta^{\prime}(i)\right]$ for all $\beta \in \mathrm{Typ}-\{\alpha\}$

Def. 4 provides abbreviations for DRS conditions which are used in the proposed meanings (Muskens 1995: 10). I refer the reader to Muskens 1995 for the semantics of the expressions below.

\section{DEFINITION 4 (DRT abbreviations)}

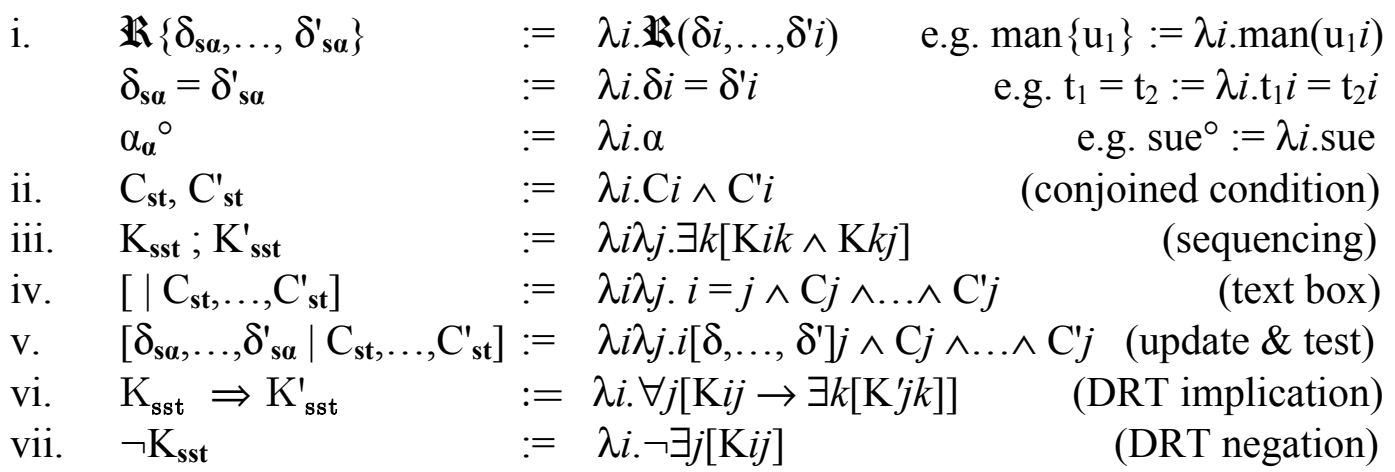

Let us now consider in more detail the proposed temporal ontology. As mentioned above, I assume an ontology consisting of time intervals and eventualities of type $\mathrm{i}$ and $\varepsilon$ respectively. Accordingly, the basic domains $\mathrm{D}_{\mathrm{i}}$ and $\mathrm{D}_{\varepsilon}$ are sets of time intervals and eventualities respectively. Following Muskens 1995 , I assume that $D_{i}$ is ordered by the complete precedence relation $<$, which is a constant of type (i(it)). This relation is then used to define the inclusion relation $\subseteq$ (cf. van Benthem 1983).

\section{DEFINITION 5}

$$
\begin{aligned}
& t \leq t^{\prime}:=\quad t<t^{\prime} \vee t=t^{\prime} \\
& t \subseteq t^{\prime}:=\quad \forall t^{\prime \prime}\left[t^{\prime}<t^{\prime \prime} \rightarrow t<t^{\prime \prime}\right] \wedge \forall t^{\prime \prime}\left[t^{\prime \prime}<t^{\prime} \rightarrow t^{\prime \prime}<t\right]
\end{aligned}
$$


Towards a more fine-grained theory of temporal adverbials

Moreover, I assume that $\mathrm{D}_{\varepsilon}$ is ordered by the part-of relation $\sqsubseteq$, which is subject to the constraint in Def. $6 .^{12}$ I assume that the domains of eventualities and time intervals are linked through a temporal trace function $\tau$, which takes an eventuality and returns its run time (Link 1987). That is, $\tau$ is a constant of type $\varepsilon i$.

\section{DEFINITION 6}

For all eventualities $e$ and $e^{\prime} \in \mathrm{D}_{\varepsilon}$ : if $e \sqsubseteq e^{\prime}$ then $\tau(e) \subseteq \tau\left(e^{\prime}\right)$

Given the temporal trace function $\tau$, each eventuality inherits the relations in Def. 5. In what follows, I will write the more concise formula $t<e$ to abbreviate $t<\tau(e)$. Similarly, I will write $e \subseteq t$ for $\tau(e) \subseteq t$.

\section{The analysis}

In this section, I would like propose an analysis for the discourse in (16) - a simplified version of (7) - using the framework outlined in the previous section.

(16) a. Sue cleaned our house on May 12, 1984.

b. That same day, Lev hired her.

To begin with, I propose to treat (16) as arising from the syntactic representation in (17).

(17) a. [тр [AdvP on May $\left.12^{\text {th }} 1984^{t_{1}}\right]\left[\right.$ тр PST [AspP PFV ${ }^{\mathrm{e}_{2}, \mathrm{t}_{2}}$ [vP Sue ${ }^{\mathrm{u}_{3}}$ clean our house $\left.\left.]\right]\right]$

b. [Tт [AdvP that same dayt $\left.t_{1}, \mathrm{t}_{2}\right]\left[{ }_{\mathrm{TP}}\right.$ PST [AspP PFV ${ }^{\mathrm{e}_{4}, \mathrm{t}_{4}}\left[\mathrm{vPP}_{\mathrm{Lev}}{ }^{\mathrm{u}_{5}}\right.$ hire her $\left.\left.\left.\left.\mathrm{u}_{3}\right]\right]\right]\right]$

I assume that anaphoric relationships are indicated in the syntax. ${ }^{13}$ I follow Barwise 1987, Muskens 1995 and others in indexing antecedents with superscripts and anaphoric expressions with subscripts, further requiring that (i) no two superscripts be the same and (ii) for each subscript $n$, where $0<n$, there be a corresponding superscript $n$. Moreover, I assume that the speech time can serve as an antecedent even though it is not introduced into the discourse context, i.e. the speech time is always accessible (van Eijck \& Kamp 1996). ${ }^{14}$ I will use $t_{0}$ to describe a constant function (of type si) from environments to the speech time.

\footnotetext{
12 For sake of simplicity, I assume that the domains of eventualities are domains of singular eventualities. If plurality is added to the theory, a Boolean structure needs to be imposed on top of the structures introduced here (Hinrichs 1985, Krifka 1989).

13 See Beaver 1999 for arguments against such an approach. I adopt it here for the sake of simplicity.

${ }^{14}$ See Bittner 2007 and Hunter 2010 where the speech time is part of the initial DRS (or in Bittner's terms: 'start-up update').
} 
With regard to the assumed phrase structure in (17), note that I will not provide meanings of VP-internal expressions because the proposed analysis is not concerned with meanings of nominal expressions. ${ }^{15}$ Moreover, I will treat all temporal adverbial expressions as syntactically on a par, i.e. as adverbial phrases, without providing the internal structure of such expressions. This is a gross idealization since an expression like currently surely has a different syntax from on May $12^{\text {th }}, 1984$ and the day after. For the current purposes, however, all that matters is that these expressions are of the same semantic type. Finally, I make the standard assumption that English sentences in the 'simple past' have a covert aspectual operator in the head of AspP. Following Kratzer 1998, Szabó 2004, Landman 2008 and others, I assume that eventive sentences have a covert perfective operator (PFV).

Let us now proceed to derive the meaning of (17) using the framework introduced in the previous section. Working bottom up, (18) provides the meaning of the VP in (17a), which is an abbreviation for the expression in (19) of type (se(sst)) - i.e. it is a function of the following kind: it takes a function from an environment to an event that has the property of being a house cleaning in that environment and returns a relation that holds between two environments $i$ and $j$ if (i) they differ maximally in the dref $u_{3}$ and (ii) the value of $u_{4}$ in the second environment $j$ is Sue, who cleans our house.

(18) $\left[\mathrm{vp}_{\mathrm{Sue}} \mathrm{Su}^{\mathrm{u}_{3}}\right.$ clean our house] $\leadsto \lambda e \cdot\left[\mathrm{u}_{3} \mid \mathrm{u}_{3}=\mathrm{sue}^{\circ}\right.$, clean.our.house $\left.\left\{\mathrm{u}_{3}, e\right\}\right]$

(19) $\lambda e \lambda i \lambda j . i\left[\mathrm{u}_{3}\right] j \wedge \mathrm{u}_{3} j=$ sue $\wedge$ clean.our.house $\left(\mathrm{u}_{3} j, e j\right)$

The meaning of the VP combines with PFV, whose meaning is provided in (20) and (21). As is standard in work on aspect, PFV requires the introduced event $\mathrm{e}_{2}$ to be contained within a time argument $t$, which (as we will see) is supplied by adverbials and serves as the REFERENCE TIME for the described event (Kamp \& Rohrer 1983, Klein 1994, von Stechow 1995, Kratzer 1998, Bary 2009). ${ }^{16}$

$$
\begin{aligned}
& {\left[\text { Asp } \mathrm{PFV}^{\mathrm{e}_{2}, \mathrm{t}_{2}}\right] \leadsto \lambda P \lambda t .\left[\mathrm{e}_{2}, \mathrm{t}_{2} \mid \mathrm{e}_{2} \subseteq t, \mathrm{e}_{2}<\mathrm{t}_{2}\right] ; P\left(\mathrm{e}_{2}\right)} \\
& \lambda P \lambda t \lambda i \lambda j . \exists k\left(i\left[\mathrm{e}_{2}, \mathrm{t}_{2}\right] k \wedge \mathrm{e}_{2} k \subseteq t k \wedge \mathrm{e}_{2} k<\mathrm{t}_{2} k \wedge P\left(\mathrm{e}_{2}\right) k j\right)
\end{aligned}
$$

Another key property of PFV is that it introduces a time $t_{2}$ that follows the described event $\mathrm{e}_{2}$ (cf. Partee 1984). This time may (though need not) serve as an antecedent in subsequent discourse. ${ }^{17}$ This is especially apparent when we consider (22), which combines the meaning in (19) and the meaning in (21).

\footnotetext{
${ }^{15}$ See Muskens 1996 and Brasoveanu 2007 for an analysis of nominal expressions within CDRT.

${ }^{16}$ Note that PFV does not really introduce an event, but rather a function from an environment to an event in that environment. I will continue to say 'event' for simplicity of exposition.

${ }^{17}$ In this way, I depart from Partee's (1984) deterministic REFERENCE TIME update.
} 
Towards a more fine-grained theory of temporal adverbials

$$
\begin{gathered}
\lambda t \lambda i \lambda j . \exists k\left(i\left[\mathrm{e}_{2}, \mathrm{t}_{2}\right] k \wedge \mathrm{e}_{2} k \subseteq t k \wedge \mathrm{e}_{2} k<\mathrm{t}_{2} k \wedge k\left[\mathrm{u}_{3}\right] j \wedge \mathrm{u}_{3} j=\text { sue } \wedge\right. \\
\text { clean.our.house } \left.\left(\mathrm{u}_{3} j, \mathrm{e}_{2} j\right)\right)
\end{gathered}
$$

According to (22), there is an environment $k$ in which the value of $t_{2}$ is after an event in $k$. We know that this time is available for anaphoric pick-up because the output environment that is passed on for the interpretation of subsequent discourse is $j$, which differs from $k$ only in the value that it assigns to $\mathrm{u}_{4}$ (and crucially not in value assigned to $t_{2}$ ). Whether the time is actually picked up as an antecedent depends on independent rules of anaphora resolution, which I do not address here. ${ }^{18}$

Let us now move on to consider the meaning of the past tense operator. As illustrated in (23)-(24), PST denotes a text box; it does not introduce a new DREF, but merely checks that the time argument precedes the speech time.

$$
\begin{aligned}
& {\left[\mathrm{T}_{\mathrm{PST}}\right] \leadsto \lambda Q \lambda t .\left[\mid t<\mathrm{t}_{0}\right] ; Q(t)} \\
& \lambda Q \lambda t \lambda i \lambda j . \exists k\left(i=k \wedge t k<\mathrm{t}_{0} k \wedge Q(t) k j\right)
\end{aligned}
$$

As the final step to deriving the meaning of (17a), consider the meaning of the adverbial phrase on May $12^{\text {th }} 1984$ in (25)-(26):

$$
\begin{aligned}
& {\left[\text { AdvP on May } 12^{\text {th }} 1984^{\mathrm{t}_{1}}\right] \leadsto \lambda Q\left[\mathrm{t}_{1} \mid \mathrm{t}_{1}=\text { may.12.1984 }\right] ; Q\left(\mathrm{t}_{1}\right)} \\
& \lambda Q \lambda i \lambda j . \exists k\left(i\left[\mathrm{t}_{1}\right] k \wedge \mathrm{t}_{1} k=\text { may.12.1984 } \wedge Q\left(\mathrm{t}_{1}\right) k j\right)
\end{aligned}
$$

Here we see that May $12^{\text {th }} 1984$ introduces a time that names May 12, 1984. In this way, it is semantically on a par with the proper name Sue, cf. (14)-(15). As we shall see shortly, that same day differs from May $12^{\text {th }}, 1984$ in (i) not introducing a new time DREF and (ii) retrieving two salient DREFs previously introduced into the discourse context.

When we combine the meanings in (18), (20), (23) and (25), we get the meaning in (27), which is an abbreviation for the expression in (28) of type sst. Note that I will henceforth use the convention of putting conditions that contain antecedents for subsequent discourse, viz. $\mathrm{e}_{2}<\mathrm{t}_{2}$, at the end of the formula.

$$
\begin{aligned}
& \text { [TP [AdvP on May } 12^{\text {th }} 1984^{\mathrm{t}_{1}} \text { ][TP PST [AspP PFV }{ }^{\mathbf{e}_{2}, \mathrm{t}_{2}} \mathrm{Sue}^{\mathrm{u}_{3}} \text { clean our house]] } \leadsto \\
& {\left[\mathrm{t}_{1}, \mathrm{e}_{2}, \mathrm{t}_{2}, \mathrm{u}_{3} \mid \mathrm{t}_{1}=\text { may.12.1984 }{ }^{\circ}, \mathrm{t}_{1}<\mathrm{t}_{0}, \mathrm{e}_{2} \subseteq \mathrm{t}_{1}, \mathrm{u}_{3}=\mathrm{sue}^{\circ}\right. \text {, }} \\
& \text { clean.our.house } \left.\left\{\mathrm{u}_{3}, \mathrm{e}_{2}\right\}, \mathrm{e}_{2}<\mathrm{t}_{2}\right]
\end{aligned}
$$

\footnotetext{
${ }^{18}$ The idea that I adopt in related work (Altshuler 2012) is that anaphora resolution reduces to satisfaction of constraints imposed by coherence relations: it can look at many anaphors at once and can appeal to world knowledge, especially when there is a lot of content available (Hobbs 1979, 1990).
} 


$$
\begin{aligned}
\lambda i \lambda j . i\left[\mathrm{t}_{1}, \mathrm{e}_{2}, \mathrm{t}_{2}, \mathrm{u}_{2}\right] j & \wedge \mathrm{t}_{1} j=\text { may.12.1983 } \wedge \mathrm{t}_{1} j<\mathrm{t}_{0} j \wedge \mathrm{e}_{2} j \subseteq \mathrm{t}_{1} j \wedge \mathrm{u}_{3} j=\text { sue } \\
& \left.\wedge \text { clean.our.house }\left(\mathrm{u}_{3} j, \mathrm{e}_{2} j\right) \wedge \mathrm{e}_{2} j<\mathrm{t}_{2} j\right)
\end{aligned}
$$

According to the meanings above, there is a time interval before the speech event that is May $12^{\text {th }}$, 1984. A house-cleaning event took place within this interval. Moreover, a time after this event is introduced and, as will be seen shortly, serves as an antecedent for the hiring event described later in the discourse.

To finish the derivation of (17), I will concentrate on the meaning of that same day in (17b). I disregard the meanings of the other expressions in (17b) because they are on a par with those in (17a). As illustrated in (29) that same requires: (i) a salient time antecedent $t_{1}$ that has the property of being a day and (ii) $t_{1}$ to have taken place throughout an already established REFERENCE TIME $t_{2}$, within which the described event takes place. ${ }^{19}$

$$
\text { [AdvP that same day } \left.\mathrm{t}_{1}, \mathrm{t}_{2}\right] \leadsto \lambda Q \cdot\left[\mid \text { day }\left\{\mathrm{t}_{1}\right\}, \mathrm{t}_{2} \subseteq \mathrm{t}_{1}\right] ; Q\left(\mathrm{t}_{2}\right)
$$

Relating (29) to the discourse at hand, notice that $t_{1}$ and $t_{2}$ are co-indexed with the drefs introduced by on May $12^{\text {th }}, 1984$ and PFV respectively. As is reflected in the meaning of (17) below, in (30), the former co-indexation allows us to capture the inference that Lev's hiring of Sue took place on May 12, 1984. The latter coindexation allows us to capture the inference that Lev's hiring of Sue took place after she cleaned his house. ${ }^{20}$

$$
\begin{aligned}
& {\left[\mathrm{t}_{1}, \mathrm{e}_{2}, \mathrm{t}_{2}, \mathrm{u}_{3}, \mathrm{e}_{4}, \mathrm{t}_{4}, \mathrm{u}_{5} \mid\right.} \\
& \text { a. } \mathrm{t}_{1}=\text { may.12.1984 }, \mathrm{t}_{1}<\mathrm{t}_{0}, \mathrm{e}_{2} \subseteq \mathrm{t}_{1}, \mathrm{u}_{3}=\text { sue }^{\circ}, \\
& \quad \text { clean.our.house }\left\{\mathrm{u}_{3}, \mathrm{e}_{2}\right\}, \mathrm{e}_{2}<\mathrm{t}_{2}, \\
& \text { b. } \left.\quad \text { day }\left\{\mathrm{t}_{1}\right\}, \mathrm{t}_{2} \subseteq \mathrm{t}_{1}, \mathrm{t}_{1}<\mathrm{t}_{0}, \mathrm{e}_{4} \subseteq \mathrm{t}_{2}, \mathrm{u}_{5}=1 e v^{\circ}, \operatorname{hire}\left\{\mathrm{u}_{5}, \mathrm{u}_{3}, \mathrm{e}_{4}\right\}, \mathrm{e}_{4}<\mathrm{t}_{4}\right]
\end{aligned}
$$

The formula in (30a) corresponds to the aforementioned truth-conditions for (17a). The formula in (30b) corresponds to the truth-conditions for (17b). It says that a hiring event took place some time within May $12^{\text {th }}, 1984$ as well as within a time after the house-cleaning event. This is the desired result.

\footnotetext{
19 As noted by Muffy Siegal (p.c.), discourses like (iii) seem to present a challenge for the proposed analysis. This discourse is felicitous even though it does not (explicitly) describe a day that could serve as an antecedent for that same day. The view advocated here is that in such instances, one accommodates an antecedent of the right kind, i.e. one that has the property of being a day. For example, in (iii), one accommodates a day three weeks ago.

(iii) Three weeks ago, Sue gave Fido a bath and cleaned our house. That same day, my wife hired her and gave her a check for one month in advance.

${ }^{20}$ Note that nothing in the meaning of that same day requires $t_{2}$ to be coindexed with the DREF introduced by PFV. This is what we want because although that same day is transparent to narrative progression, it is not a narrative progression trigger (recall discussion in section 1).
} 
Towards a more fine-grained theory of temporal adverbials

In sum, this section has provided an analysis of the discourse in (16). The key idea was that that same day is 'twice' anaphoric: it encodes two anaphoric drefs that need to be resolved. One of these drefs serves to locate the described event within a salient day previously mentioned in the discourse. The other dref serves to locate the described event within a previously mentioned REFERENCE TIME. In (17), this REFERENCE TIME is introduced by the perfective aspect, which explains why we have narrative progression; this aspect moves the REFERENCE TIME forward.

By allowing a previously established REFERENCE TIME to play such a crucial role without introducing a REFERENCE TIME of its own, that same day differs from the other adverbs discussed at the outset of the paper. This difference is summarized in Fig. 2.

\begin{tabular}{|c|c|c|c|}
\hline & ANAPHORIC & DEICTIC & INTRODUCE DREF? \\
\hline May 12, 1984 & No & No & Yes \\
\hline yesterday & No & Yes & Yes \\
\hline the day after & Yes & No & No \\
\hline that same day & Yes & No & Yes \\
\hline on Sunday & Yes & Yes & \\
\hline
\end{tabular}

Figure 2 Typology of adverbs (to be revised)

\section{Concluding thoughts with 'currently'}

In this paper I argued that a temporal adverbial need not introduce a new time DREF into the discourse context. That is, in addition to being +/- deictic and +/anaphoric, a core property of adverbial meaning is whether an adverb is $+/$ - in its ability to introduce a new time DREF. My argument was based on that same day and its transparency to narrative progression. I proposed that that same day retrieves two salient times from the input context, i.e. it is 'twice-anaphoric'. This is what I proposed to be the crucial difference between that same day and an adverb like the day after, which introduces a new DREF into the discourse context and is only 'once-anaphoric'. One question that comes up is whether there are any other temporal adverbials that also fail to introduce a new time DREF into the discourse context. I would like to suggest that currently is such an adverb. 
There is a particular use of currently where it co-occurs with the past tense and is anaphoric on a previously mentioned time. ${ }^{21}$ The discourse in (31) exemplifies such a usage, where currently refers to the time of the interview described in (31a).

(31) a. Carol was thirty-six at the time of the interview.

b. She had dropped out of high school after becoming pregnant and married at seventeen.

c. Currently she was divorced and raising her son on her own with her work as a hairdresser (Press 1991).

The idea that currently is a time-seeking anaphor is supported by the observation that (29) is somewhat odd without currently in (29c):

(32) a. Carol was thirty-six at the time of the interview.

b. She had dropped out of high school after becoming pregnant and married at seventeen.

c. \#She was divorced and raising her son on her own with her work as a hairdresser.

Here, we are led to the inference that Carol was both married and divorced. In other words, currently is needed because it serves to locate the events described in (29c) at the time of the interview described in (29a).

A challenge for the anaphoric analysis of currently comes from Kamp's (1971: 299) example in (29), which contains now. ${ }^{22}$ This example was used to argue that now always refers to the context of utterance, which would explain why (31) entails that an earthquake is taking place at the speech time (even though there is no present tense in the sentence); such an entailment disappears without now. The same point can be made about currently, viz. (34).

(33) I learned last week that there would now be an earthquake.

(34) I learned last week that there would currently be an earthquake.

I would like to suggest the following reanalysis: currently requires a salient time antecedent and the speech time must be chosen in (32) because it is compatible with the semantics of would and there is no other possible antecedent; the time of the learning event (i.e. a week before the speech time) described by the matrix clause is ruled out because would requires the earthquake to follow this event.

${ }^{21}$ Corpora reveal that currently occurs more frequently with the past tense than the present tense (see Lee 2010 for similar results with now using the British National Corpus).

${ }^{22}$ Currently, rather than now, is discussed here because now introduces various complexities that would take us too far afield (see Lee \& Choi 2009, Altshuler 2010, Hunter 2010 for discussion). 
Towards a more fine-grained theory of temporal adverbials

Evidence for this view comes from (35), which is like (34) except that it is has a possible antecedent, namely Victoria beginning to look nervous. Consequently, currently no longer refers to the speech time.

(35) ...Victoria began to look nervous, thought Jenya. She was shaking and paced back and forth. Apparently, she learned last week that there would currently be an earthquake.

In sum, the data above suggests that currently is an anaphoric expression: it requires a salient time antecedent that could be in the present or past and - if no grammatical elements (viz. the present tense) indicate otherwise-independent rules of anaphora resolution determine which one is chosen. In (34), these rules determine that the speech time is chosen; in (35) these rules determine that the onset of looking nervous is chosen.

Another key property of currently is illustrated by the discourses in (36) and (37), which suggest that this adverb is incompatible with eventive sentences. ${ }^{23}$

(36) In messages on 3 December, the British and French Governments noted that an effective United Nations Force \{\#currently arrived/ ${ }^{\mathbf{O K}}$ was currently ready to arrive $/{ }^{\mathrm{OK}}$ was currently arriving $\} .{ }^{24}$

(37) He developed the Boston Road projects for CVS, Big Y and Red Robin, and \{\#currently built/ ${ }^{\mathrm{OK}}$ was currently building\} a Hampton Inn and Suites at Founders Plaza. ${ }^{25}$

The data above are important for several reasons. To begin with, it goes against Katz's (2003) descriptive claim that some adverbs "select against stative verbs. On the other hand, the fact that there are, in fact, adverbs that "select for stative verbs and against eventive verbs", viz. currently, raises non-trivial questions about the meaning of these adverbs and, more generally, the interface between adverbial and aspectual meaning. Space limitations prevent me from addressing these questions in detail here. However, a good starting point is to say that currently is like that same day in not introducing a new time DREF but rather retrieving a salient time previously mentioned in the discourse (see Fig. 3 below). In particular, one could extend Altshuler's 2009 analysis of now to currently and say that this adverbial has both an explicitly temporal component and perspective shifting discourse component. These components conspire to impose the following two requirements: (i) search for a salient time that serves as the "current

${ }^{23}$ Cf. similar claims about now in Kamp \& Reyle 1993 and Altshuler 2009. See also Lee \& Choi 2009 and Hunter 2010 for data in which now is felicitous in eventive sentences.

${ }^{24} \mathrm{http}: / /$ www.un.org/en/peacekeeping/missions/past/unefl backgr2.html

${ }^{25} \mathrm{http} / / /$ articles.courant.com/keyword/hampden/recent/2 
perspective' and (ii) describe what took place throughout this topical time. The first requirement would capture currently's anaphoric nature, while the second leads to a contradiction with eventive, but not stative VPs. More specifically, the idea would be that aspectual constraints on narrative progression imposed by eventive (but not stative) VPs contradict the narrative progressive constraints imposed by currently. The hope is that further research will make this idea precise within the theory of temporal interpretation proposed here.

\begin{tabular}{|c|c|c|c|}
\hline & ANAPHORIC & DEICTIC & INTRODUCE DREF? \\
\hline May 12, 1984 & No & No & Yes \\
\hline yesterday & No & Yes & Yes \\
\hline the day after & Yes & No & Yes \\
\hline that same day & Yes & No & No \\
\hline currently & Yes & Yes & Yes \\
\hline on Sunday & Yes & Yes & \\
\hline
\end{tabular}

Figure 3 Typology of adverbs (final version)

\section{References}

Altshuler, Daniel. 2009. Meaning of 'now' and other temporal location adverbs. In Maria Aloni \& Katrin Schulz (eds.). Amsterdam Colloquium 2009. Heidelberg: Springer. 183-192.

Altshuler, Daniel. 2010. Temporal interpretation in narrative discourse and event internal reference. Rutgers University: PhD dissertation.

Altshuler, Daniel. 2012. Aspectual meaning meets discourse coherence: A look at the Russian imperfective. Journal of Semantics 29. 39-108. doi: 10.1093/jos/ffr008.

Asher, Nicholas. 1993. Reference to Abstract Objects. Dordrecht: Kluwer.

Barwise, John. 1987. Noun phrases, generalized quantifiers and anaphora. In Peter Gärdenfors (ed.). Generalized Quantifiers. Dordrecht: Reidel. 1-29.

Bary, Corien. 2009. Aspect in Ancient Greek. A semantic analysis of the aorist and imperfective. Radboud University, Nijmegen: PhD dissertation.

Beaver, David. 1999. The logic of anaphora resolution. In Paul Dekker (ed.). Proceedings of the Twelfth Amsterdam Colloquium. Amsterdam: Institute of Logic, Language and Computation Publications. 55-60. 
Towards a more fine-grained theory of temporal adverbials

van Benthem, Johan. 1983. The Logic of Time. Dordrecht: Kluwer.

Bittner, Maria. 2007. In Chris Barker \& Pauline Jacobson (eds.). Direct Compositionality. Oxford: Oxford University Press. 363-404.

Brasoveanu, Adrian. 2007. Temporal interpretation in narrative discourse and event internal reference. Rutgers University: PhD dissertation.

Burnett, Heather. 2012. The Role of microvariation in the study of semantic universals: Adverbial quantifiers in European and Québec French. Journal of Semantics 29. 1-38. doi: 10.1093/jos/ffr001.

Dowty, David. 1986. The effects of aspectual class on the temporal structure of discourse: semantics or pragmatics? Linguistics and Philosophy 9(1). 37-61.

van Eijck, Jan \& Hans Kamp. 1996. Representing discourse in context. In Johan van Benthem \& Alice ter Meulen (eds.). Handbook of Logic and Language. Amsterdam: Elsevier. 179-237.

Groenendijk, Jeroen \& Martin Stokhof. 1990. Dynamic Montague Grammar. In Laszlo Kalman and Laszlo Polos (eds.). Proceedings of the Second Symposion on Logic and Language. Hungary: Eotvos Lorand University Press. 3-48.

Groenendijk, Jeroen \& Martin Stokhof. 1991. Dynamic Predicate Logic. Linguistics and Philosophy 14(1). 39-100. doi: 10.1007/BF00628304.

Hinrichs, Erhard. 1985. A compositional semantics for aktionsarten and NP reference in English. Ohio State University: Dissertation.

Hobbs, Jerry. 1979. Coherence and coreference. Cognitive Science 3(1). 67-90. doi: $10.1207 / \mathrm{s} 15516709 \operatorname{cog} 030144$.

Hobbs, Jerry. 1990. Literature and Cognition. Menlo Park: CSLI.

Hunter, Julie. 2010. Presuppositional indexicals. The University of Texas, Austin: $\mathrm{PhD}$ dissertation.

Kamp, Hans. 1971. Formal properties of now. Theoria 37(3). 227-273. doi: 10.1111/j.1755-2567.1971.tb00071.x.

Kamp, Hans. 1979. Events, instants and temporal reference. In Rainer Bäuerle, Urs Egli \& Arnim von Stechow (eds.). Semantics from Different Points of View. Berlin: De Gruyter. 376-471.

Kamp, Hans. 1981. A theory of truth and semantic representation. In Jeroen Groenendijk, Theo Janssen \& Martin Stokhof (eds.). Formal Methods in the Study of Language. Amsterdam: Mathematisch Centrum Tracts.

Kamp, Hans \& Christian Rohrer. 1983. Tense in texts. In Rainer Bäuerle, Christoph Schwarze \& Arnim von Stechow (eds.). Meaning, Use and Interpretation of Language. Berlin: De Gruyter. 250-69.

Kamp, Hans \& Ewe Reyle. 1993. From Discourse to Logic: Introduction to Model theoretic Semantics of Natural Language, Formal Logic and Discourse Representation Theory. Dordrecht: Kluwer. 
Kamp, Hans \& Schiehlen, Michael. 2002. Temporal location in natural languages. In Hans Kamp \& Uwe Reyle (eds.). How we say WHEN it happens. Tübingen: Max Niemeyer Verlag. 181-233.

Katz, Graham. 2003. Event arguments, adverb selection, and the Stative Adverb Gap. In Ewald Lang, Claudia Maienborn \& Catherine Fabricius-Hanses (eds.). Modifying Adjuncts. Mouton: De Gruyter. 455-474.

Kehler, Andrew. 2002. Coherence, Reference and the Theory of Grammar. Menlo Park: CSLI.

Klein, Wolfgang. 1994. Time in Language. London: Routledge.

Knott, Alistair. 1996. A data-driven methodology for motivating a set of coherence relations. University of Edinburgh: PhD dissertation.

Knott, Alistair \& Chris Mellish. 1996. A feature-based account of the relations signaled by sentence and clause connectives. Language and Speech 39(2-3). 143-183.

Kratzer, Angelika. 1998. More structural analogies between pronouns and tenses. In Devon Strolovitch \& Aaron Lawson (eds.). Proceedings of Semantics and Linguistic Theory 8. Ithaca: Cornell University. 92-109.

Krifka, Manfred. 1989. Nominal reference and quantification in event semantics. In Renate Bartsch, Johan van Benthem \& Peter van Emde Boas (eds.). Semantics and Contextual Expression. Dordecht: Foris Publications. 75115.

Landman, Fred. 2008. 1066: On the differences between the tense-perspectiveaspect systems of English and Dutch. In Susan Rothstein (ed.), Theoretical and Crosslinguistic Approaches to the Semantics of Aspect. Amsterdam: Johns Benjamins. 107-167.

Lascarides, Alex \& Nicholas Asher. 1993. Temporal interpretation, discourse relations and commonsense entailment. Linguistics and Philosophy 16. 437493. doi:10.1007/BF00986208.

Latecki, Longin \& Manfred Pinkal. 1990. Syntactic and semantic conditions for quantifier scope. Universität des Saarlandes: Technical report.

Lee, Eunhee \& Jeongmi Choi. 2009. Two nows in Korean. Journal of Semantics 26(1). 87-107. doi:10.1093/jos/ffn012.

Lee, Eunhee. 2010. Discourse properties of 'now'. Paper presented at the 84th annual meeting of the Linguistic Society of America, January 7-10, Baltimore, Maryland.

Link, Godehard. 1987. Algebraic semantics of event structures. In Jeroen Groenendijk, Martin Stokhof \& Frank Veltman (eds.). Proceedings of the Sixth Amsterdam Colloquium. Amsterdam: University of Amsterdam. 243262. 
Towards a more fine-grained theory of temporal adverbials

Mann, William \& Sandra Thompson. 1988. Rhetorical structure theory: Toward a functional theory of text organization. Text 8(3). 243-281. doi: 10.1515/text.1.1988.8.3.243.

Moens, Marc \& Mark Steedman. 1988. Temporal ontology and temporal Reference. Computational Linguistics 14(2). 15-28.

Muskens, Reinhard. 1995. Tense and the Logic of Change. In Urs Egli, Peter E. Pause, Christoph Schwarze, Arnim von Stechow \& Götz Wienold (eds.). Lexical Knowledge in the Organization of Language. Philadelphia: John Benjamins. 147-184.

Muskens, Reinhard. 1996. Combining Montague Semantics and Discourse Representation. Linguistics and Philosophy 19. 143-186. doi: 10.1007/BF00635836.

Partee, Barbara. 1984. Nominal and Temporal Anaphora. Linguistics and Philosophy 7. 243-286.

Pratt, Jan \& Nissim Francez. 2001. Temporal Generalized Quantifiers. Linguistics and Philosophy 24. 187-222. doi: 10.1023/A:1005632801858.

Press, Andrea. 1991. Women Watching Television: Gender, Class and Generation in the American Television Experience. Philadelphia: University of Pennsylvania Press.

Ritz, Marie-Eve, Alan Dench \& Patrick Caudal. 2012. Now or then? The clitic -rru in Panyjima: Temporal properties in discourse. Australian Journal of Linguistics. 41-72. doi: 10.1080/07268602.

von Stechow, Arnim. 1995. On the proper treatment of tense. In Mandy Simons \& Teresa Galloway (eds.). Proceedings from Semantics and Linguistic Theory 5. Ithaca and New York: Cornell University. 362-386.

von Stechow, Arnim. 2002. Temporal prepositional phrases with quantifiers: Some additions to Pratt and Francez (2001). Linguistics and Philosophy 25. 755-800. doi: 10.1023/A:1020872017811.

Stone, Matthew. 1997. The anaphoric parallel between modality and tense. IRCS Report. Philadelphia: University of Pennsylvania Press. 97-06.

Szabó, Zoltan. 2004. On the progressive and the perfective. Noûs 38. 29-59.

Vegnaduzzo, Stefano. 2001. A partition semantics for temporal adverbs. University of California, Los Angeles: PhD dissertation.

Webber, Bonnie, Matthew Stone, Aravind Joshi \& Alistair Knott. 2003. Anaphora and discourse structure. Computational Linguistics 29. 545-587. doi:10.1162/089120103322753347.

Daniel Altshuler

Department of Linguistics, Heinrich-Heine-Universität Düsseldorf

Universitätsstr. 1

40225 Düsseldorf, Germany

daltshul@,gmail.com 